\title{
Overcoming Hard Water Antagonistic to Glyphosate or Imazethapyr with Water Conditioners
}

\author{
Akbar ALIVERDI ${ }^{1 *}$, Ali GANBARI ${ }^{1}$, Mohammad-Hassan RASHED MOHASSEL ${ }^{1}$, \\ Mehdi NASSIRI-MAHALLATI ${ }^{1}$, Eskandar ZAND ${ }^{2}$
}

\author{
${ }^{I}$ Department of Agronomy and Plant Breeding, College of Agriculture, Ferdowsi University of Mashhad, Mashhad, Iran \\ ${ }^{2}$ Department ofWeed Research,Plant Protection Research Institute, Tehran, Iran; akbar.aliverdi@stu.um.ac.irn (*correspondingauthor)
}

\begin{abstract}
Carrier water quality may affect the activity of weak acid herbicides when concentrations of some cations are high. A doseresponse experiment on glyphosate and imazethapyr activity, which were carried by the carrier types of distilled water and hard water, against jimsonweed were conducted to compare the water conditioning chemicals ammonium sulfate, ammonium nitrate, citric acid and potassium phosphate, with magnetized carrier as a new method. A magnetic field of 0.7 Tesla was applied to prepare the magnetized carrier. With the exception of potassium phosphate with imazethapyr, the activity of glyphosate and imazethapyr was significantly increased in the presence of the water conditioning methods when distilled water was used as the carrier. Ammonium sulfate was the most effective method. The activity of both herbicides was decreased when applied with hard water carrier. Potassium phosphate was not effective at reducing the antagonism of cations in the hard water carrier. In glyphosate, the performance of water conditioning methods in softening hard water carrier could be ranked as follows: ammonium sulfate (2.52-fold) $>$ magnetized carrier (2.12-fold) $\geq$ citric acid (1.64-fold) $\geq$ ammonium nitrate (1.39-fold) $>$ potassium phosphate ( 0.96 -fold). In imazethapyr, this order was as follows: ammonium sulfate $(2.99$-fold $)>$ ammonium nitrate $(2.66$-fold $)>$ magnetized carrier $(1.81$-fold $) \geq$ citric acid (1.64fold) $>$ potassium phosphate (1.10-fold).
\end{abstract}

Keywords: adjuvant, herbicide efficacy, jimsonweed, magnetized carrier

\section{Introduction}

Water is the most frequently used carrier for herbicide applications. Thus, its physicochemical properties in spray mixture can affect the absorption and/or activity of herbicides (Hoffmann et al., 2008). A high concentration of cations (e.g. $\mathrm{Na}^{+}, \mathrm{K}^{+}, \mathrm{Ca}^{2+}, \mathrm{Mg}^{2+}$, and $\mathrm{Fe}^{3+}$ ) in water can decrease herbicide efficacy. Weak acid herbicides that have been antagonized by one or more of the above cations include sethoxydim (Matysiak \& Nalewaja, 1999; Nalewaja et al., 1989), glyphosate (Nalewaja and Matysiak, 1991; Bernards et al., 2005; Bailey et al., 2002), 2,4-D (Roskamp et al., 2013), clethodim (Nandula et al., 2007), imazethapyr (Gronwald et al., 1993), tralkoxydim (DeVilliers et al., 2001), and glufosinate (Pline et al., 2000). This antagonism is due to the formation of herbicide salts with a low solubility, resulting in a reduction in retention on the leaves (Hoffmann et al., 2008) and/or a reduction in absorption into the plant (Nalewaja et al., 1996). As a result, a decrease in herbicidal performance is observed. When 2,4-D amine is mixed with hard water, a sediment may form in lines, filters, nozzles or the bottom of the spray tank (Nalewaja et al., 1991). Approaches to minimize hard water antagonism have included decreasing the spray carrier volume (Wills et al., 1998) and using water-conditioning additives (Thelen $e t$ al., 1995a) which have proven effective at ameliorating cation-caused antagonism include ammonium sulfate (Soltani et al., 2011), ammonium nitrate, potassium phosphate (Wills et al., 1998), and citric acid (Thelen et al., 1995b).

Passing hard water containing $\mathrm{Ca}^{2+}$ (Kobe et al., 2001; Kobe et al., 2002; Plavic et al., 1999; Cho and Choi, 1998; Madsen, 2004; Coey and Cass, 2000), $\mathrm{Mg}^{2+}$ or $\mathrm{Na}^{+}$(Bin et al., 2011) through an external magnetic device results in the nucleation and crystallization of the respective carbonates. As a result, hard water can be conditioned for a period known as the 'magnetic memory of water' (Colic and Morse, 1999). Magnetized water may induce a change in water physicochemical properties such as conductivity (Sueda et al., 2007), surface tension (Cho and Lee, 2005), viscosity (Quinn et al., 1997), vaporization rate (Toledo et al., 2008), and $\mathrm{pH}$ (Fathi et al., 2006). All the aforementioned physicochemical factors can affect the performance of post-emergence herbicides (Rao, 2000).

The objectives of this research were (i) to investigate the effect of hard water on glyphosate and imazethapyr efficacy, and (ii) to compare chemical water conditioners (ammonium sulfate, ammonium nitrate, citric acid and 
potassium phosphate) with a physical method that consist spray carrier passage through a magnetic field for ameliorating the antagonistic effect of hard water on glyphosate and imazethapyr activity against jimsonweed.

\section{Materials and methods}

\section{Plant growth}

Seeds of jimsonweed (Datura stramonium L.) were collected from plants in the fields of Qazvin city, Iran, during November 2012. They were stored in the dark at room temperature until use. Bioassays were conducted between June 2013 and September 2013 in a greenhouse located on the Ferdowsi University of Mashhad, Iran. To increase seed germination before starting the experiment, the seeds were washed every 1 hour for 7 days to remove seed germination inhibitors, according to Andersen (1968). Twenty-five jimsonweed seeds were sown at $0.5 \mathrm{~cm}$ depth in $2 \mathrm{~L}$ plastic pots filled with a mixture of sand, clay loam soil, and peat $(1: 1: 1 \mathrm{v} / \mathrm{v})$. Up to $88 \%$ of the seeds were emerged. At the one- and two-leaf stages, the seedlings were thinned to a final population of four uniform plants per pot. After each thinning, plants were fertilized twice with $20 \mathrm{~mL}$ of a water-soluble N:P:K (20:20:20) fertilizer, at a concentration of $3 \mathrm{~g}$ of fertilizer per liter of tap water. The pots were irrigated every three days with tap water. Treatments were sprayed at the four-leaf stage.

\section{Treatments and chemicals}

The treatments were six doses of glyphosate $(0,12.81$, $25.62,51.25,102.5$ and $205 \mathrm{~g}$ a.i. ha $\left.{ }^{-1}\right)$ or imazethapyr $(0$, $4.69,9.38,18.75,37.5$ and $75 \mathrm{~g}$ a.i. of imazethapyr $\mathrm{ha}^{-1}$ ) which were carried by the carrier types included of: (i) distilled water and (ii) hard water with and without the water conditioning methods included of: (i) ammonium sulfate $\left(\left(\mathrm{NH}_{4}\right)_{2} \mathrm{SO}_{4}\right)$ at $20 \mathrm{~g} \mathrm{~L}^{-1}$; (ii) ammonium nitrate $\left(\mathrm{NH}_{4} \mathrm{NO}_{3}\right)$ at $20 \mathrm{~g} \mathrm{~L}^{-1}$; (iii) potassium phosphate $\left(\mathrm{KHPO}_{4}\right)$ at $20 \mathrm{~g} \mathrm{~L}^{-1}$; (iv) citric acid $\left(\mathrm{C}_{6} \mathrm{H}_{8} \mathrm{O}_{7}\right)$ at $20 \mathrm{~g} \mathrm{~L}^{-1}$; and (v) passing 10 times through a magnetic field. Glyphosate isopropylamine $(41 \% \mathrm{SL})$ and imazethapyr $(10 \% \mathrm{SL})$ were used. The concentrations of the water conditioning chemicals were selected based on recommendations of Somervaille et al. (2012) and Wills et al. (1998). After checking the water samples of Mashhad region, Iran, the Sand-Washing Well in Tangal-shor village located at $36.20^{\circ}$ North latitude and $59.35^{\circ}$ East longitude was chosen to obtain hard water. The chemical composition of hard water was: $\mathrm{Na}^{+}=3722 \mathrm{ppm}, \mathrm{K}^{+}=14 \mathrm{ppm}, \mathrm{Ca}^{2+}=501 \mathrm{ppm}$, $\mathrm{Mg}^{2+}=573 \mathrm{ppm}, \mathrm{SO}_{4}^{-}=56.1 \mathrm{meq} \cdot \mathrm{L}^{-1}, \mathrm{CO}_{3}^{-}=0.5 \mathrm{meq} \cdot \mathrm{L}^{-1}$, $\mathrm{HCO}_{3}^{-}=3.1$ meq. $\mathrm{L}^{-1}, \mathrm{Cl}^{-}=165.1$ meq. $\mathrm{L}^{-1}, \mathrm{EC}=23.0 \mathrm{dS}$. $\mathrm{m}^{-1}$, and $\mathrm{pH}=8.4$. Treatments were applied at $180 \mathrm{~L} \mathrm{ha}^{-1}$ at $200 \mathrm{kPa}$ using a calibrated moving boom sprayer with an 8002 flat-fan nozzle (Spraying Systems Co., Wheaton, IL). A magnetic treatment device was devised and used for magnetizing the carriers. The arrangement of the permanent magnetic field and the dimensions of its different parts are shown in Fig. 1, which was involved a 20 $\mathrm{cm}$ copper tube with a rectangular channel $(21 \mathrm{~mm}$ length and $1 \mathrm{~mm}$ width) flowed the solution between two pieces of magnet placed on either side of the copper tube. The maximum strength of the magnetic field was measured to be up to 0.7 Tesla by using a magnetometer (Model 1-ST;
AlphaLab, Salt Lake City, Utah, USA). Gabrielli et al. (2001) indicated that the influence depend upon the pathway length in the magnetic field and the flow rate. Therefore, the carriers were passed 10 times through the magnetic device to magnetize effectively. Shoots were harvested four weeks after treatment, dried for $48 \mathrm{~h}$ at $70^{\circ} \mathrm{C}$, and dry weight was determined. The experiment was performed again under the same conditions.

\section{Statistical analysis}

Data of shoot dry weight were subjected to a non-linear regression analysis for determination of $\mathrm{ED}_{10}, \mathrm{ED}_{50}$, and $\mathrm{ED}_{90}$ values (herbicide dose needed to obtain $10 \%, 50 \%$, $90 \%$ reduction in dry weight, respectively) using the following logarithmic logistic dose-response model (Ritz \& Streibig, 2005):

$$
Y=C+\{D-C / 1+\exp [B(\log X-\log E)]\}
$$

Where $\mathrm{Y}$ is the response (shoot dry weight), $\mathrm{C}$ is the lower limit, $\mathrm{D}$ is the upper limit, $\mathrm{B}$ is the slope of the curve, $\mathrm{E}$ is the required dose of herbicide to give $50 \%$ control; and $\mathrm{X}$ is the herbicide dose. The validity of the model 1 and the comparisons between the parameters were made using an Ftest for lack-of-fit at the $0.05 \%$ level of significance. If no significant lack of fit was detected when model 1 was tested, the model was acceptable. The relative potency $(\mathrm{R})$ was the horizontal displacement between the two curves and was calculated using the ratio of doses producing the same response, as follows:

$$
R=E D_{50 a} / E D_{50 b}
$$

where $\mathrm{ED}_{50 \mathrm{a}}$ is for the treatment of ' $\mathrm{a}$ ' and $\mathrm{ED} \mathrm{D}_{50 \mathrm{~b}}$ is for the treatment of ' $b$ '. If $R<1$, treatment ' $a$ ' is more potent than treatment ' $b$ ' and if $R>1$, the reverse is correct. Data were analyzed to determinate the parameters by opensource statistical software, $\mathrm{R}_{2.62 .2}$, utilizing the $d r c$ statistical addition package. By using PROC PROBIT in SAS software, data of $\mathrm{ED}_{50}$ were subjected to analysis of each experiment in confidence interval of $95 \%$ to determine whether the two runs of the experiments differed from each other or not. The results of one run will be discussed, as these were similar both runs.

\section{Results}

The $\mathrm{ED}_{10}, \mathrm{ED}_{50}$, and $\mathrm{ED}_{90}$ values in distilled water for jimsonweed were 11.40, 35.47, and $109.14 \mathrm{~g}$ a.i. of glyphosate $a^{-1}$, respectively (Tab. 1). These values were $6.02,13.95$, and $32.34 \mathrm{~g}$ a.i. of imazethapyr ha ${ }^{-1}$, respectively. The glyphosate $\mathrm{ED}_{90}$ rate under greenhouse conditions was about $53 \%$ of the recommended rate $\left(205 \mathrm{~g}_{\text {a.i. }} \mathrm{ha}^{-1}\right)$ while the imazethapyr $\mathrm{ED}_{90}$ rate was about $57 \%$ of the recommended rate ( $75 \mathrm{~g}$ a.i. ha $\left.{ }^{-1}\right)$ when distilled water was used as carrier. As judged by the relative potency values given in Tab. 1, the values were considerably higher than 1 , indicating the enhanced glyphosate activity with addition/application of water conditioning methods when distilled water was used as carrier. With the exception of potassium phosphate with imazethapyr, the activity of both herbicides against jimsonweed was significantly increased in 
the presence of the water conditioning methods when distilled water was used as the carrier. They were ranked based on their performance to improve glyphosate activity as follows: ammonium sulfate (4.03-fold) > citric acid ( 2.81 -fold $) \geq$ ammonium nitrate $(2.35$-fold $) \geq$ magnetized carrier $(2.10$-fold $) \geq$ potassium phosphate $(1.97$-fold).
Moreover, they were ranked based on their performance to improve imazethapyr activity as follows: ammonium sulfate (3.52-fold $)>$ ammonium nitrate $=$ citric acid $(2.58$-fold $)>$ magnetized carrier $(1.83$-fold $)>$ potassium phosphate (1.28-fold).

Activity of both herbicides was decreased when applied

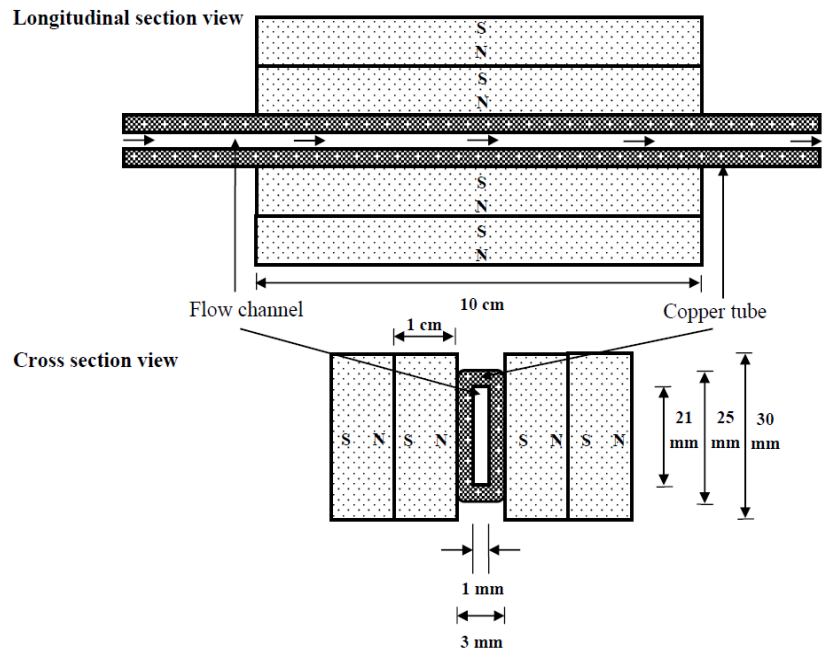

Fig. 1. Magnetic treatment device; N-North pole, S-South pole

Tab. 1. Estimated parameters for the response curves of jimsonweed treated with glyphosate or imazethapyr applied with the different carriers alone or in the presence of water conditioners

\begin{tabular}{|c|c|c|c|c|c|c|c|c|c|c|}
\hline Herbicide & Carrier & Water conditioner & B & $\begin{array}{c}\mathrm{ED}_{10} \\
\left(\text { g a.i. }^{-1} \mathrm{ha}^{-1}\right)\end{array}$ & $\begin{array}{c}\mathrm{ED}_{50} \\
\left(\mathrm{~g}^{-1 . i .} \mathrm{ha}^{-1}\right)\end{array}$ & $\begin{array}{c}\mathrm{ED}_{90} \\
\left(\text { (g a.i. }^{-1}{ }^{-1}\right)\end{array}$ & \multicolumn{2}{|c|}{ Relative potency } & \multicolumn{2}{|l|}{$\begin{array}{l}\text { Relative } \\
\text { potency }\end{array}$} \\
\hline \multirow[t]{12}{*}{ Glyphosate } & Distilled water & Non & $1.94(0.37)$ & $11.40(2.41)$ & $35.47(4.31)$ & $109.14(9.47)$ & 1.00 & c & & \\
\hline & & Ammonium sulfate & $1.47(0.60)$ & $2.01(1.42)$ & $8.81(1.81)$ & $39.76(8.12)$ & $4.03(0.93)$ & $\mathrm{g}$ & & \\
\hline & & Ammonium nitrate & $2.34(0.68)$ & $5.88(1.52)$ & $14.98(1.28)$ & $38.19(10.32)$ & $2.35(0.35)$ & f & & \\
\hline & & Citric acid & $1.43(0.54)$ & $2.69(1.51)$ & $12.53(1.77)$ & $58.31(3.42)$ & $2.81(0.52)$ & f & & \\
\hline & & Potassium phosphate & $2.11(0.69)$ & $6.31(1.61)$ & $17.83(1.78)$ & $50.42(5.17)$ & $1.97(0.31)$ & e & & \\
\hline & & Magnetized carrier & $2.01(0.58)$ & $5.61(1.63)$ & $16.76(1.76)$ & $50.00(6.44)$ & $2.10(0.33)$ & ef & & \\
\hline & Hard water & Non & $2.41(0.55)$ & $27.34(5.07)$ & $67.79(8.63)$ & $168.08(8.90)$ & $0.52(0.09)$ & a & 1.00 & $\mathrm{a}$ \\
\hline & & Ammonium sulfate & $2.03(0.45)$ & $9.11(2.24)$ & $26.82(3.06)$ & $78.94(12.71)$ & $1.31(0.23)$ & de & $2.52(0.43)$ & d \\
\hline & & Ammonium nitrate & $2.12(0.41)$ & $17.24(3.57)$ & $48.53(5.96)$ & $136.61(5.73)$ & $0.72(0.13)$ & $\mathrm{b}$ & $1.39(0.24)$ & b \\
\hline & & Citric acid & $1.99(0.37)$ & $13.73(2.80)$ & $41.29(5.79)$ & $124.15(5.65)$ & $0.85(0.16)$ & bc & $1.64(0.31)$ & bc \\
\hline & & Potassium phosphate & $1.64(0.40)$ & $19.75(4.79)$ & $75.14(7.52)$ & $285.89(7.61)$ & $0.46(0.12)$ & a & $0.96(0.23)$ & a \\
\hline & & Magnetized carrier & $2.01(0.39)$ & $10.67(2.41)$ & $31.86(3.98)$ & $95.07(5.74)$ & $1.10(0.20)$ & c & $2.12(0.37)$ & c \\
\hline \multirow[t]{12}{*}{ Imazethapyr } & Distilled water & Non & $2.61(0.48)$ & $6.02(0.91)$ & $13.95(1.22)$ & $32.34(5.90)$ & 1.00 & d & & \\
\hline & & Ammonium sulfate & $1.93(0.60)$ & $1.27(0.46)$ & $3.96(0.41)$ & $12.33(3.16)$ & $3.52(0.46)$ & h & & \\
\hline & & Ammonium nitrate & $2.56(0.72)$ & $2.28(0.47)$ & $5.39(0.39)$ & $12.70(2.74)$ & $2.58(0.27)$ & $\mathrm{g}$ & & \\
\hline & & Citric acid & $2.27(0.65)$ & $2.05(0.49)$ & $5.39(0.42)$ & $14.15(3.46)$ & $2.58(0.28)$ & $\mathrm{g}$ & & \\
\hline & & Potassium phosphate & $2.64(0.59)$ & $4.10(0.67)$ & $9.41(0.68)$ & $21.58(3.79)$ & $1.28(0.25)$ & d & & \\
\hline & & Magnetized carrier & $2.13(0.46)$ & $2.73(0.51)$ & $7.63(0.66)$ & $21.36(4.68)$ & $1.83(0.21)$ & f & & \\
\hline & Hard water & Non & $3.75(0.69)$ & $15.78(1.89)$ & $28.33(2.20)$ & $50.87(7.44)$ & $0.49(0.06)$ & a & 1.00 & a \\
\hline & & Ammonium sulfate & $2.72(0.61)$ & $4.22(0.83)$ & $9.45(0.79)$ & $21.16(4.23)$ & $1.47(0.18)$ & e & $2.99(0.34)$ & d \\
\hline & & Ammonium nitrate & $3.09(0.67)$ & $5.23(0.68)$ & $10.63(0.99)$ & $21.61(4.73)$ & $1.41(0.17)$ & de & $2.66(0.32)$ & d \\
\hline & & Citric acid & $3.60(0.84)$ & $9.34(1.56)$ & $17.18(1.15)$ & $31.61(4.65)$ & $0.81(0.09)$ & c & $1.64(0.16)$ & c \\
\hline & & Potassium phosphate & $3.03(0.71)$ & $11.72(1.85)$ & $24.16(2.30)$ & $49.77(1.30)$ & $0.57(0.04)$ & b & $1.10(0.14)$ & b \\
\hline & & Magnetized carrier & $2.73(0.60)$ & $6.99(1.26)$ & $15.61(1.42)$ & $34.86(7.61)$ & $0.89(0.11)$ & c & $1.81(0.21)$ & c \\
\hline
\end{tabular}

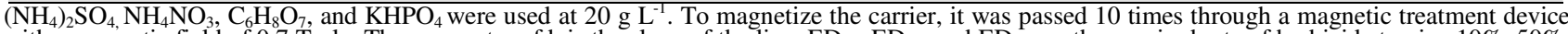
with a magnetic field of 0.7 Tesla. The parameter of $\mathrm{b}$ is the slope of the line. $\mathrm{ED}_{10}, \mathrm{ED}_{50}$, and $\mathrm{ED}_{90}$ are the required rate of herbicide to give $10 \%$, $50 \%$, and $95 \%$ control, respectively. The standard errors are in parentheses. In each column, relative potencies followed by same letter are not significantly different at the 0.05 probability level 
with the carrier of hard water (Fig. 2). Based on comparison to distilled water, the $\mathrm{ED}_{90}$-values of glyphosate and imazethapyr increased about 35\% and 37\% when they were added to hard water, respectively. In both herbicides, the antagonisms caused by hard water were significantly ameliorated by the addition of ammonium sulfate, citric acid, and ammonium nitrate, and by the application of magnetizing the carrier (Tab. 1). Potassium phosphate was not effective at reducing the antagonism of cations in the hard water carrier. In glyphosate, the performance of water conditioning methods in softening hard water carrier could be ranked as follows: ammonium sulfate $(2.52$-fold $)>$ magnetized carrier $(2.12$-fold $) \geq$ citric acid $(1.64$-fold $) \geq$ ammonium nitrate (1.39-fold) > potassium phosphate (0.96-fold). In imazethapyr, this order is partly changed as follows: ammonium sulfate (2.99-fold) > ammonium nitrate $(2.66$-fold $)>$ magnetized carrier $(1.81$-fold $) \geq$ citric acid (1.64-fold) $>$ potassium phosphate (1.10-fold) .
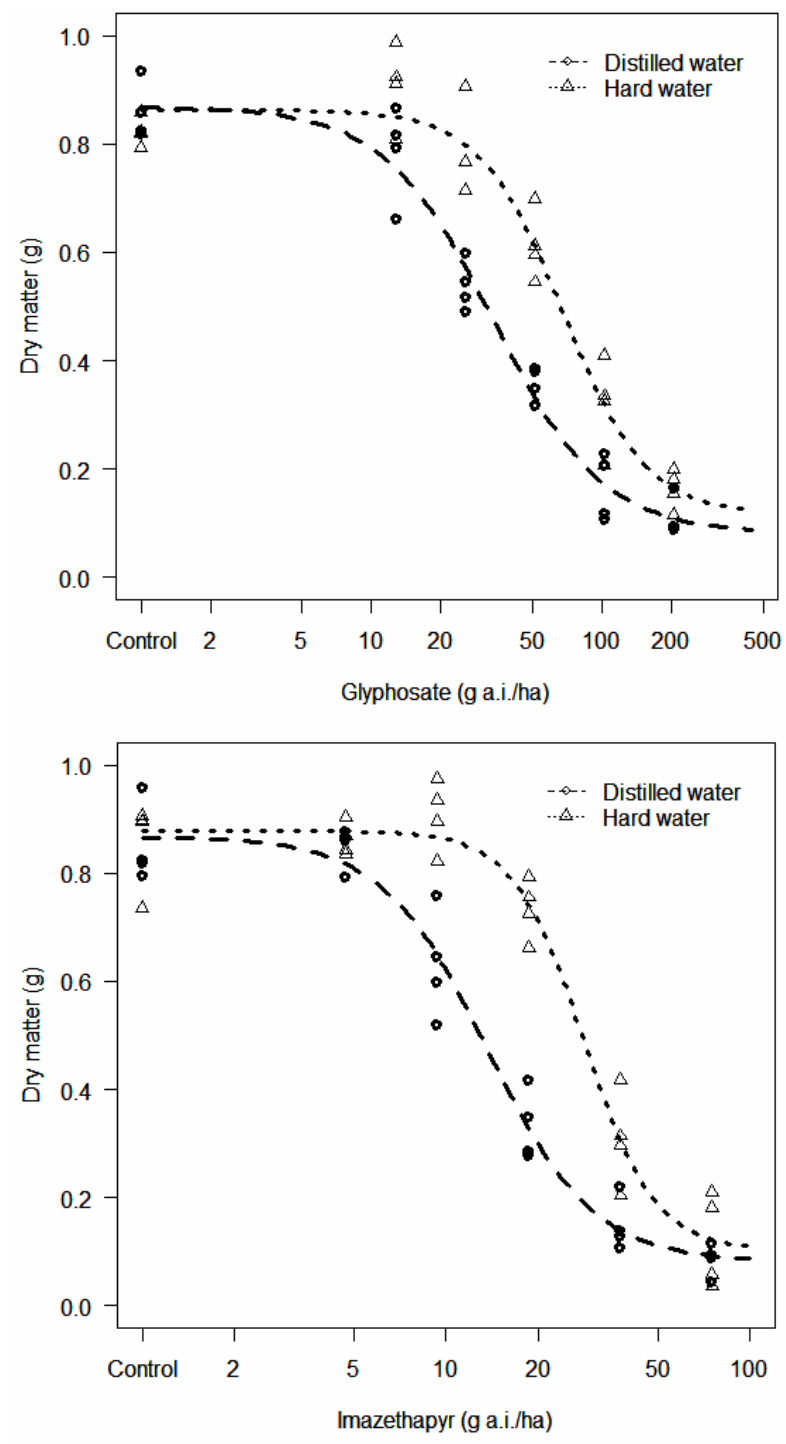

Fig. 2. Log-logistic dose-response for shoot dry weight of jimsonweed (Datura stramonium L.) to imazethapyr or glyphosate when they were applied with the carriers of distilled water (o) and hard water $(\Delta)$. The $r^{2}$ values for the regression model were 0.98 and 0.96 for distilled and hard water, respectively

\section{Discussion}

Enhancement of herbicidal activity by water conditioning chemicals in distilled water confirms the results by Nurse et al. (2008), Thelen $e t$ al. (1995a), Pline et al. (1999), and Molin and Hirase (2004). Although enhancement of glyphosate or imazethapyr activity by the application of magnetized carrier has not been reported, passing cycloxydim and clodinafop-propargyl solutions through a magnetic field did result in increased herbicide activity (Rashed-Mohassel et al., 2009). They believed that the increased activity was related to a reduction in surface tension of the spray solution which then produces smaller droplets. Due to a lower level of energy existing in smaller droplets retention of the droplets is increased and the contact angle of the droplet on the leaf surface is reduced. These may increase absorption of active ingredient by the leaves (Penner, 2000). It is also reported that chemical water conditioning methods may adjust the spray solution $\mathrm{pH}$ so that more of the active ingredient is transported across the leaf surface and into the plant (Pline et al., 1999).

Activity of both herbicides was clearly antagonized in our bioassays by the presence of $\mathrm{Na}^{+}, \mathrm{Mg}^{2+}$, and $\mathrm{Ca}^{2+}$ in the hard water used. This confirms data reported by Pratt et al. (2003) and Nurse et al. (2008). The dose-response curves with distilled water and hard water were not parallel and suggested that the antagonism was greatest at lower glyphosate or imazethapyr doses. Because the glyphosate or imazethapyr molecule has a negative charge in alkali solution, they can react with the cations in spray solution; leading to the formation of glyphosate-salt or imazethapyrsalt complexes which having a greater difficulty being absorbed into the plant (Pratt et al., 2003). In addition, the presence of the cations in spray solution increases the droplet size, allowing less retention and/or absorption of active ingredient by the leaves (Hoffmann et al., 2008).

The antagonism caused by the cations existing in hard water carrier in the tested herbicides was significantly overcome by all water conditioning methods, except potassium phosphate. The ability of water conditioners to negate glyphosate incompatibilities with cations in water has been reported (Nalewaja and Matysiak, 1993). Ammonium sulfate was the most successful method of ameliorating decreased herbicidal activity due to antagonism with $\mathrm{Na}^{+}, \mathrm{Mg}^{2+}$, or $\mathrm{Ca}^{2+}$ in the spray solution. By adding ammonium sulfate, the sulfate ion $\left(\mathrm{SO}_{4}^{-}\right)$ conjugates with the hard water cations and removes free cations from solution by forming cation- $\mathrm{SO}_{4}$ molecule, allowing ammonium ion $\left(\mathrm{NH}_{4}^{+}\right)$to form herbicide- $\mathrm{NH}_{4}$ molecule (Thelen et al., 1995a). Similarly, by adding ammonium nitrate, the nitrate ion $\left(\mathrm{NO}_{3}^{-}\right)$conjugates with the hard water cations to form cation- $\mathrm{NO}_{3}$ molecule, thus allowing $\mathrm{NH}_{4}^{+}$to form herbicide- $\mathrm{NH}_{4}$ molecule (Penner, 2006). A herbicide- $\mathrm{NH}_{4}$ molecule diffuses across the cuticle easier and quicker than the herbicide-salt molecule (Thelen et al., 1995a). Moreover, Macisaac et al. (1991) suggested that ammonium sulfate reduces the crystallization of glyphosate on the plant surface. By adding citric acid, a stronger conjugate base (negative portion) is provided (Thelen et al., 1995b; Nalewaja et al., 2007), allowing to the 
248

acid binds to and removes positively charged cations from solution (Pline et al., 2000).

A mechanism for water conditioning by magnetizing water is facilitating the nucleation and crystallization. Herzog et al. (1989) reported that in the presence of an external magnetic field, the nucleation and crystallization of calcium carbonate in hard water can be greatly increased. Afterwards, the crystallization of calcium (Wang et al., 1997; Kobe et al., 2001; Kobe et al., 2002; Plavic et al., 1999; Cho and Choi, 1998; Madsen, 2004; Coey and Cass, 2000), magnesium and sodium carbonates (Bin et al., 2011) in hard water was confirmed when it was passed through a magnetic field. Since dissolved ions in hard water have either negative charge, namely $\mathrm{CO}_{3}^{-}, \mathrm{HCO}_{3}^{-}, \mathrm{SO}_{4}^{-}$, or $\mathrm{Cl}^{-}$or positive charge, namely $\mathrm{K}^{+}, \mathrm{Na}^{+}, \mathrm{Mg}^{2+}, \mathrm{Ca}^{2+}$, or $\mathrm{Fe}^{3+}$, they are agitated by passing a magnetic field. The positively charged ions are attracted by the $\mathrm{N}$ pole and the negatively charged ions were attracted by the $S$ pole of the magnet. Therefore, the collision among the positive and negative ions increases, facilitating the nucleation and crystallization (Cho and Choi, 1998). The latter will allow removing free cations from solution, leaving the herbicidal molecule unrestrained, without forming herbicide-salt complex. On the other hand, previous studies has been discovered that the size in contact angles of magnetized water on the surface of silica gel decreases (Feng and Bo, 2008), thus the surface tension of magnetized water decreases relative to that of distilled water (Rashed-Mohassel $e t$ al., 2009), producing smaller droplets which may lead to increased retention and/or absorption of active ingredient (Penner, 2000).

\section{Conclusions}

With the exception of potassium phosphate, all water conditioning methods overcame the antagonism that was observed, especially ammonium sulfate. Although the application of magnetized carrier as a new method was not an effective method as much as the addition of ammonium sulfate, from the point of view of environmental and agricultural, applying magnetized carrier will be benefit because it needs no chemical. A systematic research is thus required to improve water conditioning physical method via using paramagnetic substances to facilitate the nucleation and crystallization (Goncharuk et al., 2009) or filtering after magnetization to remove the formed crystals (Fathi et al., 2006).

\section{Acknowledgments}

This work was conducted in partial fulfilment of requirements for the Ph.D. degree (Project No. 3/23293) in Weed Science at Ferdowsi University of Mashhad that was funded by a grant from the College of Agriculture. Appreciation is also extended to Mrs. Somayeh Ebrahimpour Faraji and Mr. Parviz Hossieni who provided invaluable assistance in conducting this research.

\section{References}

Andersen RN (1968). Germination and establishment of weeds for experimental purposes. In: A Weed Science Society of America Handbook (ed. by Andersen RN). Weed Science Society of America, Urbana, IL, USA.

Bailey WA, Poston DH, Wilson HP, Hines TE (2002). Glyphosate interactions with manganese. Weed Technol 16: 792-799.

Bernards ML, Thelen KD, Penner D (2005). Glyphosate efficacy is antagonized by manganese. Weed Technol 19:27-34.

Bin G, Haibo H, Feng C (2011). Influence of magnetic field on micro structural and dynamic properties of sodium, magnesium and calcium ions. $\mathrm{T}$ Nonferr Metal Soc 21:494-498.

Cho YI, Choi BG (1998). Electronic anti-fouling technology to mitigate precipitation fouling in plate-and-frame heat exchangers. Int J Heat Mass Transfer 41:2565-2571.

Cho YI, Lee SH (2005). Reduction in the surface tension of water due to physical water treatment for fouling control in heat exchangers. Int Commun Heat Mass 32:1-9.

Coey JMD, Cass S (2000). Magnetic water treatment. J Magn Magn Mater 209:71-74.

Colic M, Morse D (1999). The elusive mechanism of the magnetic 'memory' of water. Colloid Surface A 154:167174.

Devilliers B, Kudsk P, Smit JJ, Mathiassen SK (2001). Tralkoxydim: adjuvant, MCPA and other effects. Weed Res 41:547-556.

Fathi A, Mohamed T, Claude G, Maurin G, Mohamed BA (2006). Effect of magnetic water treatment on homogeneous and heterogeneous precipitation of calcium carbonate. Water Res 40:1941-1950.

Feng PX, Bo D (2008). The macroscopic changes of features and microscopic structures of water under influence of magnetic field. Physica B 403:3571-3577.

Gabrielli C, Jaouhari R, Maurin G, Keddam M (2001). Magnetic water treatment for scale prevention. Water Res 35:3249-3259.

Goncharuk VV, Bagrii VA, Chebotareva RD, Bashtan SY, Nanieva AV (2009). Crystallization of calcium carbonate in magnetized water in the presence of paramagnetic substances. J Water Chem Technol 31:172-176.

Gronwald JW, Jourdan SW, Wyse DL, Somers DA, Magnusson MU (1993). Effect of ammonium sulfate on absorption of imazethapyr by quackgrass (Elytrigia repens) and maize (Zea mays) cell suspension cultures. Weed Sci 41:325-334.

Herzog RE, Shi Q, Patil JN, Katz JL (1989). Magnetic water treatment: the effect of iron on calcium carbonate nucleation and growth. Langmuir 5:861-867.

Hoffmann WC, Bagley WE, Fritz BK, Lan Y, Martin DE (2008). Effects of water hardness on spray droplet size under aerial application conditions. Appl Eng Agric 24:1114.

Kobe S, Drazic G, Cefalas AC, Sarantopoulou E, Strazisar J (2002). Nucleation and crystallization of $\mathrm{CaCO}_{3}$ in 
applied magnetic fields. Crystal Eng 5:243-253.

Kobe S, Drazic G, Mcguiness PJ, Strazisar J (2001). The influence of the magnetic field on the crystallization form of calcium carbonate and the testing of a magnetic watertreatment device. J Magn Magn Mater 236:71-76.

Macisaac SA, Paul RN, Devine MD (1991). A scanning electron microscope study of glyphosate deposits in relation to foliar uptake. Pestic Sci 31:53-64.

Madsen HEL (2004). Crystallization of calcium carbonate in magnetic field in ordinary and heavy water. J Cryst Growth 267:251-255.

Matysiak R, Nalewaja JD (1999). Temperature, adjuvants, and UV light affect sethoxydim phytotoxicity. Weed Technol 13:94-99.

Molin WT, Hirase K (2004). Comparison of commercial glyphosate formulations for control of prickly sida, purple nutsedge, morningglory and sicklepod. Weed Bio Manag 4:136-141.

Nalewaja JD, Devilliers B, Matysiak R (1996). Surfactant and salt affect glyphosate retention and absorption. Weed Res 36:241-247.

Nalewaja JD, Manthey FA, Szelezniak EF, Anyska A (1989). Sodium bicarbonate antagonism of sethoxydim. Weed Technol 3:654-658.

Nalewaja JD, Matysiak R (1991). Salt antagonism of glyphosate. Weed Sci 39:622-628.

Nalewaja JD, Matysiak R (1993). Optimizing adjuvants to overcome glyphosate antagonistic salts. Weed Technol 7:337-342.

Nalewaja JD, Woznica Z, Matysiak R (1991). 2,4-D Amine antagonism by salts. Weed Technol 5:873-880.

Nalewaja JD, Woznica Z, Szeleznak EF, Ramsdale B (2007). Sequence of tank-mixing water conditioning adjuvants and herbicides. Proceedings of the 8th International Symposium on Adjuvants for Agrochemicals. International Society for Agrochemical Adjuvants (ISAA). Columbus, Ohio, USA.

Nandula VK, Poston DH, Reddy KN, Koger CH (2007). Formulation and adjuvant effects on uptake and translocation of clethodim in bermudagrass (Cynodon dactylon). Weed Sci 55:6-11.

Nurse RE, Hamill AS, Kells JJ, Sikkema PH (2008). Annual weed control may be improved when AMS is added to below-label glyphosate doses in glyphosate-tolerant maize (Zea mays L.). Crop Prot 27:452-458.

Penner D (2000). Activator adjuvants. Weed Technol 14:785791.

Penner D (2006). Novel water conditioning agents for glyphosate. North Central Weed Science Society Proceedings 61:150.

Plavic B, Kobe S, Orel B (1999). Identification of crystallization forms of $\mathrm{CaCO}_{3}$ with ftir spectroscopy. Metal Alloy Technol 33:517-521.

Pline WA, Hatzios KK, Hagood ES (2000). Weed and herbicideresistant soybean (Glycine max) response to glufosinate and glyphosate plus ammonium sulfate and pelargonic acid. Weed Technol 14:667-674.

Pline WA, Wu J, Hatzios KK (1999). Effects of temperature and chemical additives on the response of transgenic herbicide-resistant soybeans to glufosinate and glyphosate applications. Pestic Biochem Phys 65:119-131.

Pratt D, Kells JJ, Penner D (2003). Substitutes for ammonium sulfate as additives with glyphosate and glufosinate. Weed Technol 17:576-581.

Quinn CJ, Molden TC, Sanderson CH (1997). Magnetic treatment of water prevents mineral build-up. Iron Steel Eng 74:47-53.

Rao VS (2000). Principles of Weed Science. $2^{\text {nd }}$ edn. Science Publishers, Enfield, NH.

Rashed-Mohassel MH, Aliverdi A, Ghorbani R (2009). Effects of a magnetic field and adjuvant in the efficacy of cycloxydim and clodinafop-propargyl on the control of wild oat (Avena fatua). Weed Bio Manag 9:300-306.

Ritz C, Streibig JC (2005). Bioassay analysis using R. J Stat Softw 12:1-22.

Roskamp JM, Chahal GS, Johnson WG (2013). The effect of cations and ammonium sulfate on the efficacy of dicamba and 2,4-D. Weed Technol 27:72-77.

Soltani N, Nurse R, Robinson D, Sikkema P (2011). Effect of ammonium sulfate and water hardness on glyphosate and glufosinate activity in corn. Can J Plant Sci 91:1053-1059.

Somervaille A, Betts G, Gordon B, Green V, Burgis M, Henderson R (2012). Adjuvants - oils, surfactants and other additives for farm chemicals. Grains Research and Development Corporation. Conservation Farmers Inc. Australia.

Sueda M, Katsuki A, Nonomura M, Kobayashi R, Tanimoto Y (2007). Effects of high magnetic field on water surface phenomena. J Phys Chem 111:14389-14393.

Thelen KD, Jackson EP, Penner D (1995a). The basis for the hard water antagonism of glyphosate activity. Weed Sci 43:541-548.

Thelen KD, Jackson EP, Penner D (1995b). Utility of nuclear magnetic resonance for determining the molecular influence of citric acid and an organosilicone adjuvant on glyphosate activity. Weed Sci 43:566-571.

Toledo EJL, Ramalho TC, Magriotis ZM (2008). Influence of magnetic field on physical-chemical properties of the liquid water: insights from experimental and theoretical models. J Mol Struct 888:409-415.

Wang Y, Babchin AJ, Chernyi LT, Chow RS, Sawatzky RP (1997). Rapid onset of calcium carbonate crystallization under the influence of a magnetic field. Water Res 31:346350.

Wills GD, Hanks JE, Jones EJ, Mack RE (1998). Effect of oil adjuvants and nitrogen fertilizer on the efficacy of imazethapyr applied at conventional and ultra low spray volumes. Weed Technol 12:441-445. 